\title{
EFFECT OF LASER PREHEATING AISI 4140 SPECIMENS FOR MICRO-FORGING
}

\begin{abstract}
Many high performance and permanent service parts require suitable material characteristics-high fatigue strength is one of the most important characteristics. For this reason, surface treatment processes are essential to increase the material performance and avoid the use of costly ineffective material. There exist various surface treatment processes for various applications. Each process has advantages and disadvantages and hybridization can solve various problems. The micro-forging process delivers a controlled and uniform surface hardness, but the depth of the forged surface is limited. On the other hand, laser heat treatment can increase the hardness drastically, but the surface may become brittle, which reduces the fatigue life. Laser-assisted micro-forging is a novel hybrid process of laser heat treatment and micro-forging that has the potential to increase the forging depth and relax the stress caused by the high temperature of the forging process.

This study examines the effect of laser preheating in the micro-forging of AISI 4140. The processes were varied as follows: no treatment, micro-forging only, and laser-assisted micro-forging. The fatigue strength of the specimens was examined by means of an ultrasonic fatigue tester and then compared. The microstructural changes were investigated with respect to the processes by using scanning electron microscopy. In conclusion, it was confirmed that the laser preheating auxiliary forging affects the fatigue life. It was confirmed that the fatigue life was the mostly increased in $550^{\circ} \mathrm{C}$ temperature laser preheating micro forging process and the temperature was identified as the most important factor.
\end{abstract}

Keywords: Laser preheating, Micro-forging, Fatigue strength, Ultrasonic fatigue test, Hardness

\section{Introduction}

By high-performance and long-life machine is developed, the surface treatment method has been variously studied that can produce a large effect at a low cost. A high-frequency microforging process has been highlighted as a method capable of fine-tuning the range and centuries.

Existing high-frequency micro-forging processes use actuators that vibrate at a frequency of approximately $9 \mathrm{kHz}$ with strong forces [1]. In these micro-forging processes, the hardness of the metal surface increases and residual stress is caused by the impact of the vibrating tip. Thus, it is possible to adjust the desired location and strength, such that it becomes a localized surface treatment. However, using a striking force on the surface has a disadvantage in that it results in the formation of a thin hardened layer.

Prior to this study, two factors were measured by the microindentation tester. These results were compared with a finite element method (FEM) simulation. The specimens were treated by a high-frequency micro-forging device, which is the same as that used in this study. They were tested by a micro-indentation tester, and measured for residual stress using the indenting depth and load. The hardness and residual stress of surface area increased.
Moreover, a minimum residual stress of $400 \mathrm{MPa}$ was measured within a depth of $0.3 \mathrm{~mm}$. Furthermore, the hardness increased rapidly within a depth of $0.1 \mathrm{~mm} \mathrm{[2].}$

In addition, laser heat treatment is used as a surface treatment. After the surface treatment, the irradiation areas have a high hardness due to the large temperature difference between the irradiation areas and the surroundings. However, this method also has a disadvantage of causing brittleness. If the surface becomes hard, the brittleness will increase. Moreover, the temperature of the surface is a problem when the laser melts the material. It can cause uneven surface roughness and material composition.

The surface hardness and residual stress of a material are very important factors that affect fatigue life. However, as previously mentioned, the existing methods have advantages and disadvantages. The micro-forging treatment and heat treatment can be complementary for simultaneous use. The increase of temperature will change the properties of the metal [3]. Specifically, it is expected that a deeper forging effect will occur by changing the stress-strain curve. In this study, we propose an auxiliary preheating high-cycle micro-forging method in order to reduce the disadvantages of the individual processes. The method is for providing the deeper effect then before by processing the pre-heating in addition to the existing method.

\footnotetext{
DEPARTMENT OF MECHANICAL ENGINEERING, AJOU UNIVERSITY, SUWON, 443-749, REPUBLIC OF KOREA

Corresponding author: princaps@ajou.ac.kr
} 


\section{Experimental}

\subsection{Micro-forging system}

We developed the experimental system based on existing micro-forging systems. A tungsten tip attached to a magnetostrictive actuator is used for the forging device. The magnetostrictive actuator is made of Tefenol-D, which can generate large forces and high frequency movement. This actuator was assembled at the tool post of a lathe. Table 1 shows the details of the forging condition.

TABLE 1

Experimental forging conditions

\begin{tabular}{|c|c|c|}
\hline Property & Value & Unit \\
\hline Tip end radius & 1.25 & $\mathrm{~mm}$ \\
\hline Specimen rotation speed & 30 & $\mathrm{RPM}$ \\
\hline Impact frequency & 9160 & $\mathrm{~Hz}$ \\
\hline Impact power & 951 & $\mathrm{~N}$ \\
\hline Tip feed speed & 0.8 & $\mathrm{~mm} / \mathrm{min}$ \\
\hline
\end{tabular}

The impact frequency was determined based on the resonance of the forging device. A laser Doppler velocimeter (LDV) was used to measure the frequency and displacement of the tip. The LDV measurements were carried out at the no-load condition, and the distance of the tip was found to be $16 \mu \mathrm{m}$ from peak to peak. The impact power was calculated using the distance and force, as shown in Eq. 1 [4]. The calculated force is $1,019 \mathrm{~N}$, but it could not have been transferred fully. This is attributed to the rebound displacement of the main body at the moment of impact. Because of this, actual displacement associated with the forces is $14 \mu \mathrm{m}$, and the actual force is $951 \mathrm{~N}$.

$$
F_{t}=m_{t} \times\left(2 \pi \times f_{t}\right)^{2} \times d_{t}
$$

\subsection{Laser Preheating Micro-forging system}

The system was composed of a micro-forging system with a laser preheating device. A diode laser was selected as the source, which was used for the heat treatment of the metal surface. It is possible to use this laser efficiently as it shows good absorption of the metal, and is easily applicable in the industry. However, only the auxiliary preheating level was required. The laser power was controlled by a pyrometer, which detects the temperature of the irradiated area. Details of the laser used are summarized in Table 2.

TABLE 2

Summary of laser specification

\begin{tabular}{|c|c|c|}
\hline Property & Value & Unit \\
\hline Wavelength & 980 & $\mathrm{~nm}$ \\
\hline Beam type & circle & \\
\hline Beam diameter & 3 & $\mathrm{~mm}$ \\
\hline Laser power & 500 & $\mathrm{~W}$ \\
\hline Pyrometer sampling rate & 20 & $\mathrm{~ms} / \mathrm{time}$ \\
\hline
\end{tabular}

The selected laser was installed on the lathe vertically, and it irradiated the test sample, which was placed perpendicular to the forging direction. The fatigue test sample was rotated, so that the micro-forging process could be performed after the laser irradiation. Fig. 1 shows this detail.

Based on the characteristics of the pyrometer that was used, the measurement accuracy decreased at temperatures lower than $350^{\circ} \mathrm{C}$. For this reason, the first and lowest test temperature was $400^{\circ} \mathrm{C}$, and the second was $550^{\circ} \mathrm{C}$. This is the highest temperature that does not cause local melting of the surface. In addition, the untreated sample was prepared for comparison with the result of the sample at $20^{\circ} \mathrm{C}$, standard temperature.

In order to achieve an accurate irradiation time, the laser was controlled by a proximity sensor that counts the number of turns of the sample. According to this sensor, preheating initiated at one revolution prior to forging, and was stopped at the same time as the forging. Based on the forging speed, the laser preheating time was $115 \mathrm{rev}$. (230 sec).

After undergoing irradiation with forging, the specimens were gradually cooled at room temperature until there was no temperature differential.

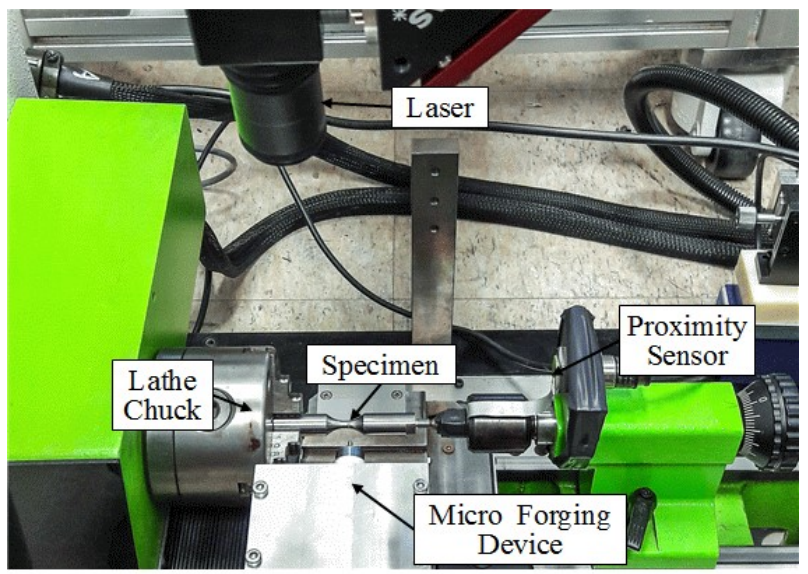

a)

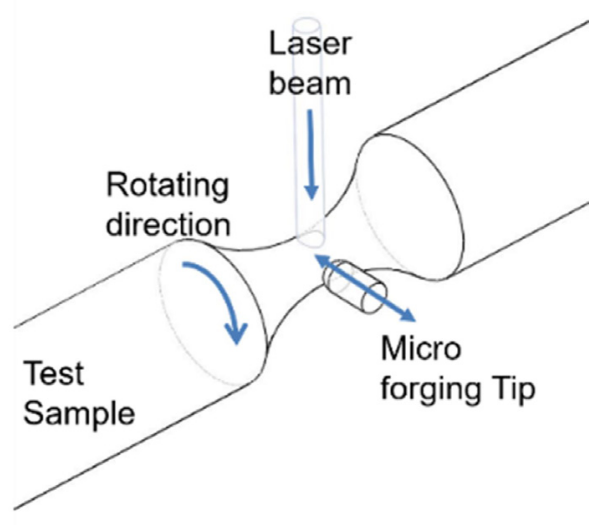

b)

Fig. 1. (a) Equipment setting, (b) Process of laser preheating micro-forging system 


\subsection{Ultra-Sonic Fatigue test}

The ultra-sonic fatigue test was conducted after the surface treatment was applied on the basis of the conditions as described in Table 3.

TABLE 3

Ultra-sonic fatigue test condition

\begin{tabular}{|c|c|c|}
\hline \hline Property & Value & Unit \\
\hline Test frequency & 20.068 & $\mathrm{kHz}$ \\
\hline Stress ratio (R) & -1 & \\
\hline On/off pulse time & $0.3 / 5$ & sec/pulse \\
\hline Cooling & \multicolumn{2}{|c|}{ Compressed air } \\
\hline Test stress & 325,335 & $\mathrm{MPa}$ \\
\hline
\end{tabular}

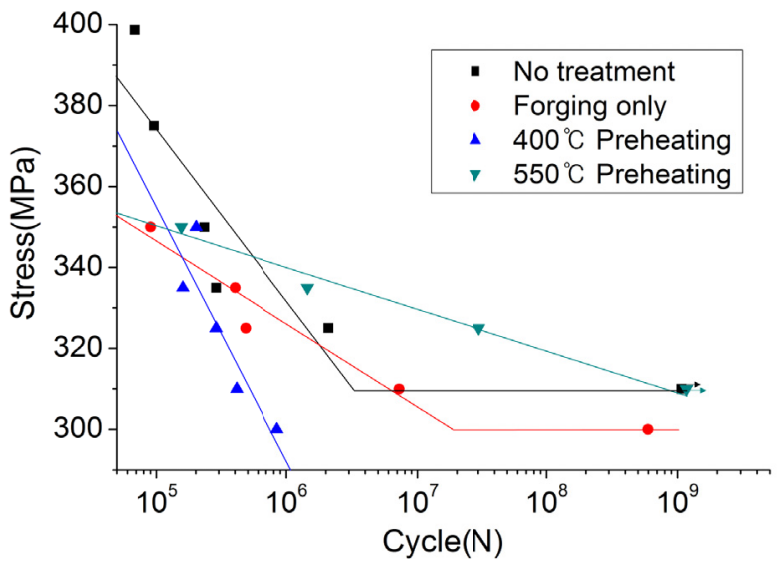

a)

\subsection{Hardness test}

Previous studies confirmed that the surface hardness were increased after treatments $[2,5,6]$. However, there was no previous study on the effect of the surface hardness with laser preheating and micro forging at the same time. The Vickers hardness tests were made from the $100 \mu \mathrm{m}$ below the surface to the center with $100 \mu \mathrm{m}$ interval and $100 \mathrm{~g}$ loads.

\section{Results and discussion}

Fig. 2 shows the results of the fatigue testing at each temperature setting. When the specimen completes $10^{9}$ cycles, the test is stopped and the endurance limit stress is determined. The

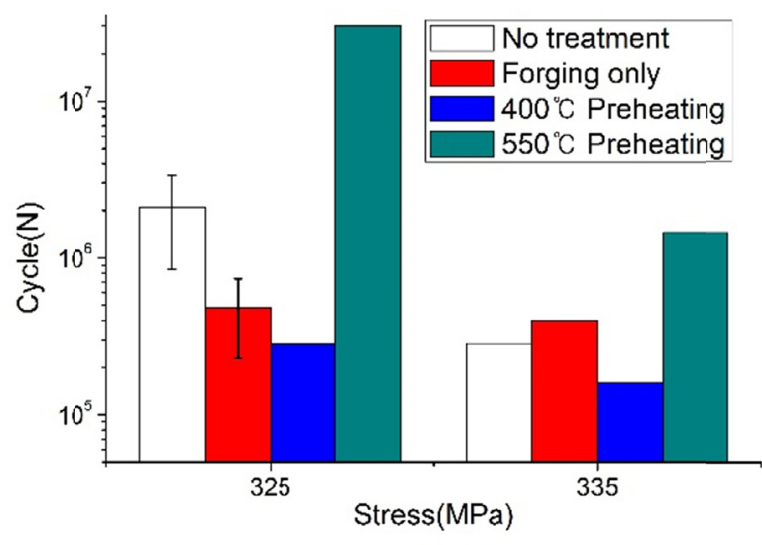

b)

Fig. 2. (a) Fatigue life of Ultra-Sonic Fatigue test, (b) Compare test result at 325, $335 \mathrm{MPa}$

arrow points at the right end of Fig. 2. indicate an unbroken specimen. The untreated sample and standard room temperature sample have a similar cycle. The $550^{\circ} \mathrm{C}$ sample exhibited the longest fatigue life at both temperatures. The $400^{\circ} \mathrm{C}$ temperature sample failed earlier than the others. In Fig. 2a), the standard error of the measurement results at $325 \mathrm{MPa}$ were indicated by an error bar. The laser specimens were measured only one at a time because of the process cost.

Fig. 3 shows the result of Vickers hardness measurement. The measurement were made for the base material, micro forging only, and micro forging with $550^{\circ} \mathrm{C}$ laser preheating cases. The results indicated that both treated cases had higher hardness measurement than the base material. The micro forging with $550^{\circ} \mathrm{C}$ laser preheating case had the highest at near surface (less than $100 \mu \mathrm{m}$ ) and this helped to increase the fatigue life. However, the micro forging only case had the higher than laser preheated micro forging case after $100 \mu \mathrm{m}$. This might happen due to the annealing effect by the laser heating.

The fracture surface of the $235 \mathrm{MPa}$ test sample was scanned using a FE-SEM (Field Emission Scanning Electron Microscope) in order to locate the crack initiation. The scanned image of the untreated sample is shown in Fig. 4. A 140X scale

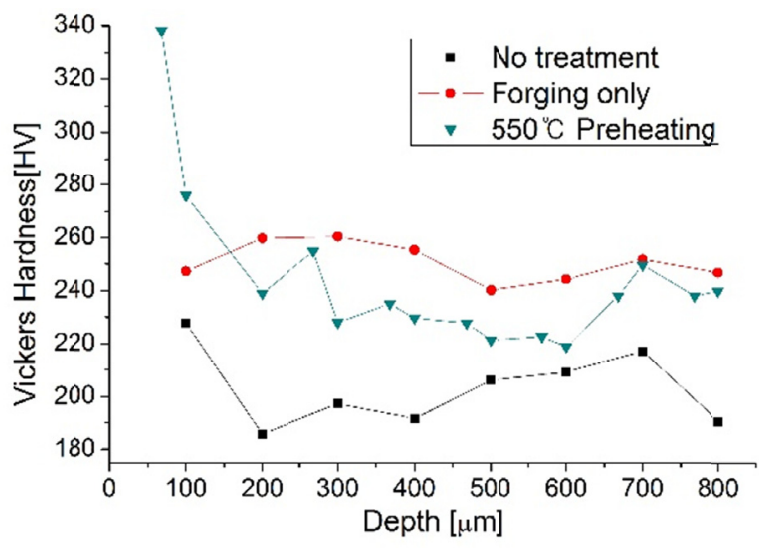

Fig. 3. Vickers hardness result

scan was used for the coarse observation, and a $1800 \mathrm{X}$ scale scan for the fine view used to locate inclusions. The untreated sample has a $7 \mu \mathrm{m}$ inclusion that has the appearance of a fisheye fracture. Thus, energy dispersive spectroscopy (EDS) was performed at the inclusion and in the surrounding area for comparison. Fig. 5 show these spectrometry areas [7]. 


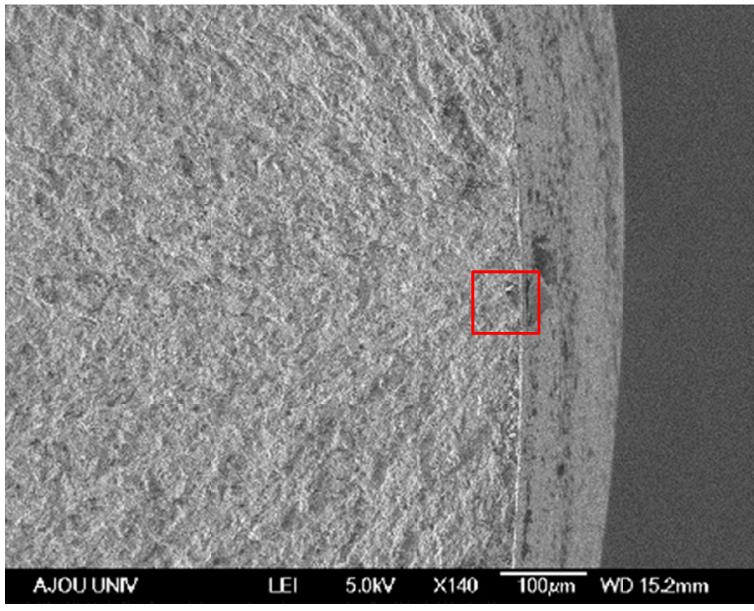

a)

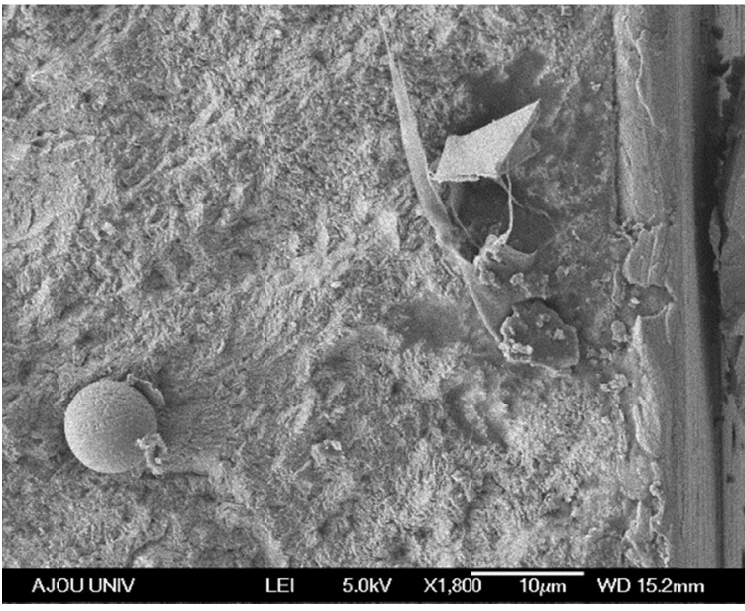

b)

Fig. 4. Fracture surface of no treatment sample at $325 \mathrm{MPa}$, (a) 140X, (b) 1800X scale

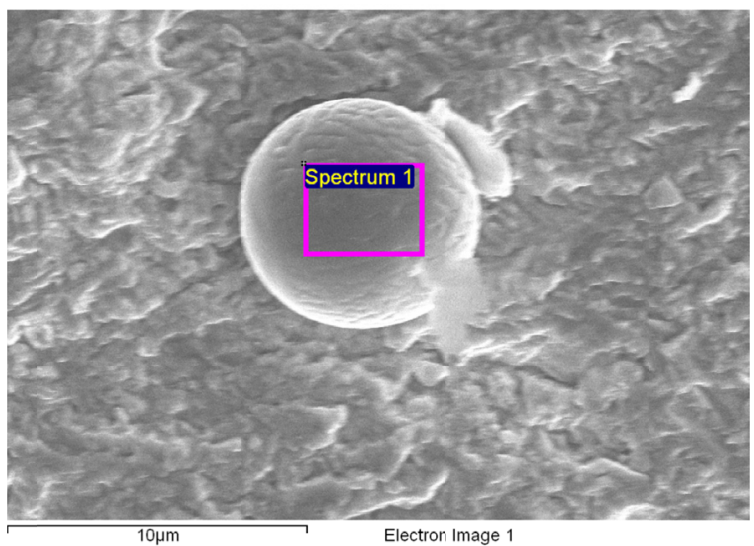

a)

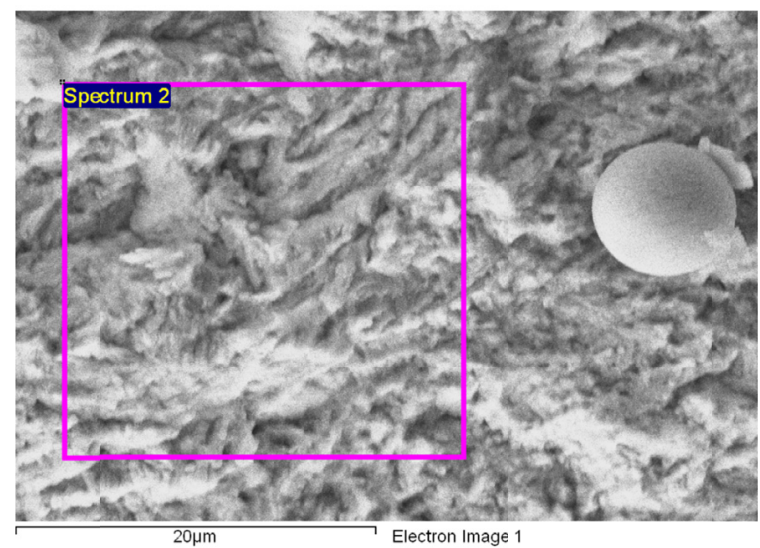

b)

Fig. 5. Fracture surface of no treatment sample at $325 \mathrm{MPa}$, (a) 140X, (b) 1800X scale

Table 5 shows the theoretical composition and the results of the EDS. The EDS machine has an observational error of less than $1 \mathrm{wt} . \%$. Thus, limited elements were detected. The inclusion is composed of iron and oxygen. In comparison, the area surrounding the inclusion shows significantly different results.

TABLE 5

Elemental composition of AISI 4140 [weight (\%)] [8]

\begin{tabular}{|c|c|c|c|c|c|c|c|c|c|}
\hline \hline Element & C & Cr & Fe & Mn & Mo & P & Si & S & O \\
\hline Standard & 0.43 & 1.1 & 97.77 & 1.0 & 0.25 & 0.035 & 0.3 & 0.04 & - \\
\hline Inclusion & & & 55.18 & & & & & & 44.82 \\
\hline Comparison & & 1.42 & 98.68 & & & & & & \\
\hline
\end{tabular}

The scan images of the other samples are shown in Fig. 6 and 7. The cracks in both of these samples initiated at their surfaces. The forging-only specimen has a $12 \mu \mathrm{m}$ thick dark area at the surface. In order to analyze this area, a number of material engineering tests will be performed in the future.

\section{Conclusions}

In this study, it was founded that the laser preheating micro forging system has an effect on fatigue life. The results of fatigue testing at each temperature show that the untreated sample and standard room temperature sample have a similar fatigue life. The $550^{\circ} \mathrm{C}$ sample obtained the highest result at both stress points. The $400^{\circ} \mathrm{C}$ sample failed before the others. Perhaps the transition temperature was in the range of $400^{\circ} \mathrm{C}$ to $550^{\circ} \mathrm{C}$, which is classified as annealing and quenching. As a result, the $400^{\circ} \mathrm{C}$ sample was annealed, and has a shorter fatigue life than the $550^{\circ} \mathrm{C}$ and the standard-temperature samples.

However, there is an unclear point at $350 \mathrm{MPa}$. The intersection point of the trend line is near the $350 \mathrm{MPa}$ test stress. In order to define the effect of surface treatment, material engineering tests are required. Moreover, for accurate stress-life curves, further fatigue tests are required.

Therefore, research into the micro-forging mechanism is required in a follow-up study. Measurement of the effective depth of the surface treatment through micro-indentation mapping is required to quantify the effect. An electron backscatter diffrac- 


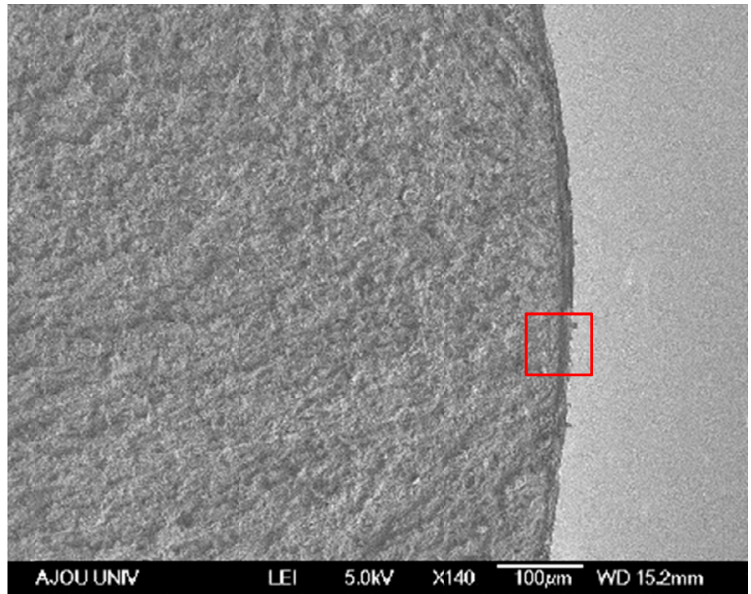

a)

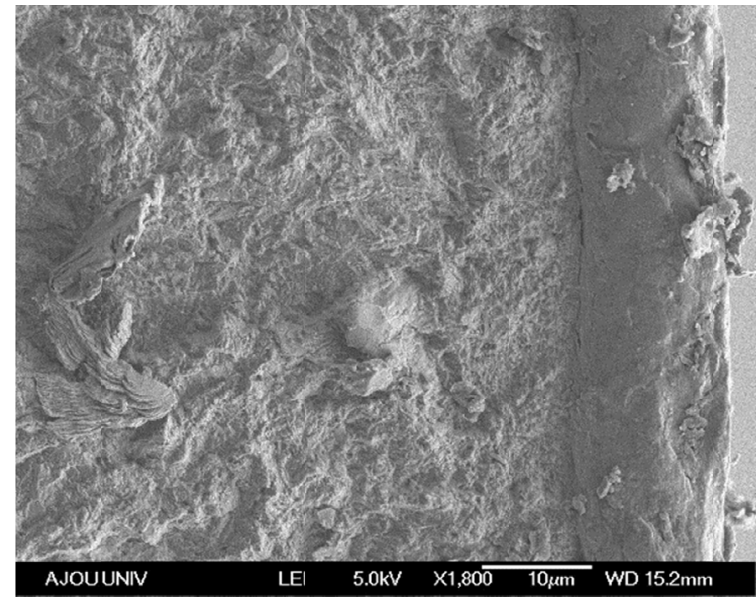

b)

Fig. 6. Fracture surface of standard temp' forging sample at $325 \mathrm{MPa}$, (a) 140X, (b) 1800X scale

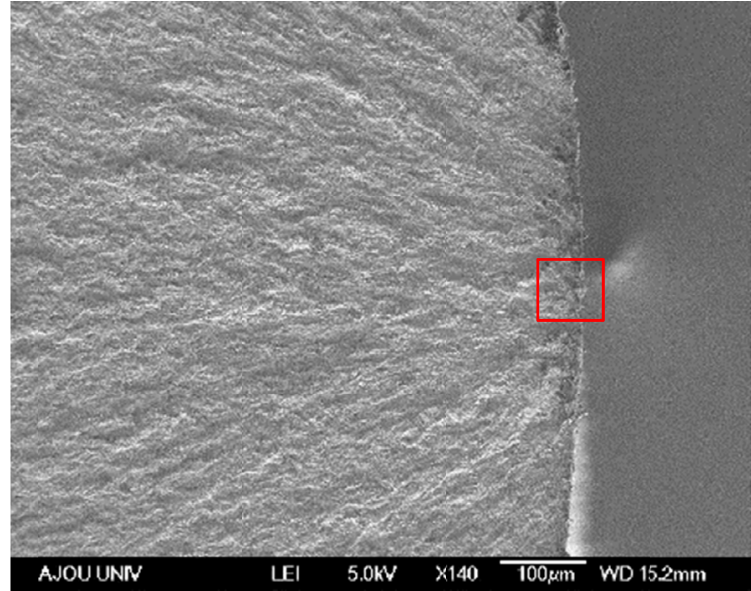

a)

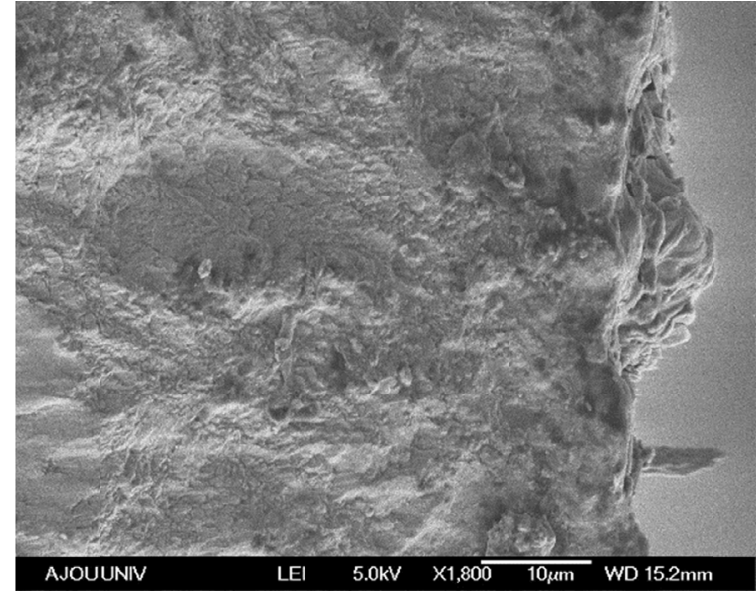

b)

Fig. 7. Fracture surface of $550^{\circ} \mathrm{C}$ forging sample at $325 \mathrm{MPa}$, (a) $140 \mathrm{X}$, (b) $1800 \mathrm{X}$ scale

tion scan at the surface will be helpful to define the mechanism of failure.

After the mechanism of failure has been investigated, the fatigue data will be used to design higher performance and longer-life products. Moreover, this surface treatment will be effective from the perspective of cost.

\section{Acknowledgments}

This research was supported by Basic Science Research Program through the National Research Foundation of Korea (NRF) funded by the Ministry of Science, ICT \& Future Planning (No. NRF - 2015R1C1A1A02036547)

\section{REFERENCES}

[1] B.J. Choi, Y. Jeon, M.G. Lee, H.J. Kim, D.K. Kim, Analysis of Micro Forging System for Straightness of Vibration Tip. Korea society for precision engineering 2016 autumn conference, 863863. (2015).
[2] C.H. Jung, M.G. Lee, J.N. Park, Y. Jeon, FEM simulation and experimental validation of residual stress on surface by micro forging processes, International Conference on Surface Modification Technologies (2016).

[3] W.S. Lee, G.W. Yeh, The Plastic Deformation Behavior of AISI 4340 Alloy Steel Subjected to High Temperature and High Strain Rate Loading Conditions, Journal of Materials Processing Technology 71.2, 224-34 Web. (1997).

[4] http://www.etrema.com/cu18a-ultrasonic-actuator.

[5] K. Dai, L. Shaw, Comparison between shot peening and surface nanocrystallization and hardening processes, Materials Science and Engineering A 463 (1-2), 46-53 (2007).

[6] M.C. Oh, H. Yeom, Y. Jeon, B. Ahn, Microstructural Characterization Of Laser Heat Treated AISI 4140 Steel With Improved Fatigue Behavior, Archives of Metallurgy and Materials 60, 2 (2015).

[7] Y. Furuya, H. Hirukawa, T. Kimura, M. Hayaishi, Gigacycle Fatigue Properties of High-Strength Steels According to Inclusion and ODA Sizes, Metall. and Mat. Trans. A 38 (8), 1722-1730 (2007). doi:10.1007/s11661-007-9225-3.

[8] M. L. Bauccio, Materials Park, ASM engineering materials reference book, OH: ASM, 1994. 